\title{
Peminjaman Inkubator Gratis Bagi Bayi Prematur
}

\author{
Free Incubator Loan for Premature Babies \\ Pipin Sumantrie*, Martalina Limbong \\ Akademi Keperawatan Surya Nusantara Pematangsiantar, Sumatra Utara, Indonesia \\ *pipinsitorus99@gmail.com
}

Riwayat Artikel: Dikirim 15 Oktober 2020; Diterima 19 November 2020; Diterbitkan 30 November 2020

\begin{abstract}
Abstrak
Laporan Perserikatan Bangsa-Bangsa (PBB) in 2010 yang berjudul "Born Too Soon, The Global Action Report on Preterm Birth", menempatkan Indonesia pada urutan 5 sebagai negara dengan jumlah bayi prematur terbanyak di dunia. Hal ini di dukung data Biro Pusat Statistik 2016, angka kematian bayi (AKB) mencapai 25 kematian setiap 1.000 bayi yang lahir. Pelaksanaan kegiatan pengabdian kepada masyarakat (PKM) ini, melalui strategi pendekatan kepada masyarakat dalam bentuk promosi peminjaman inkubator gratis kepada para keluarga yang memiliki bayi-bayi yang prematur. Pendekatan dilakukan secara langsung (direct approach) dengan menggunakan komunikasi yang efektif kepada para tenaga kesehatan, maupun pihak kelurahan yang terdapat di sekitar wilayah kerja. Dengan kegiatan PKM inkubator gratis yang telah dilakukan, banyak para orang tua yang memiliki bayi BBLR merasa tertolong dan sangat berterimakasih, proses peminjaman inkubator yang telah di pinjamkan kepada para orang tua berkisar antara 1 sampai 2 bulan, namun ada juga pihak keluarga yang meminjam lebih dari 3 bulan. Hal ini dikarenakan kondisi bayi yang sulit berkembang. Dengan tersedianya peminjaman inkubator portable gratis yang dilakukan oleh Relawan Inkubator Gratis Akademi Keperawatan Surya Nusantara, bekerja sama dengan Yayasan Bayi Prematur Indonesia, para masyarakat Pematangsiantar dan sekitarnya merasa tertolong, dan sangat berterimakasih, bukan hanya para bayi yang merasa nyaman dengan berada di dalam inkubator tersebut, para orang tua juga merasa bahagia, dan tidak kuatir akan perkembangan bayi mereka, dan mereka tidak perlu mengalami stress sehubungan dengan pembiayaan dalam perawatan bayi prematur, karna alat inkubator dan alat fototerapi blue light di pinjamkan secara gratis tanpa di pungut biaya sepeser pun.
\end{abstract}

Kata Kunci: Bayi Prematur, Inkubator, Fototherapi

\begin{abstract}
The United Nations (UN) in 2010 report entitled "Born Too Soon, The Global Action Report on Preterm Birth" placed Indonesia in fifth place as the country with the highest number of premature babies in the world. This was supported by data from the Central Bureau of Statistics in 2016, saying the infant mortality rate (IMR) reached 25 deaths per 1,000 babies born. The implementation of the community service (PKM) is through a strategic approach to the community in the form of promoting free incubator lending to families with premature babies. The approach is carried out directly (direct approach) by using effective communication to bealth workers, as well as to urban villages around the work area. With the free incubator, many parents who have $L B W$ babies feel helped and are very grateful, the incubator lending process that has been loaned to parents ranges from 1 to 2 months, but there are also families who borrow more than 3 months. This is because the baby's condition is difficult to develop. With the availability of free portable incubator loans carried out by the Surya Nusantara Nursing Academy Free Incubator Volunteers, in collaboration with the Indonesian Premature Baby Foundation, the people of Pematansgiantar and its surroundings feel helped, and are very grateful, not only that the babies who feel comfortable being in the incubator but also the parents also who feel happy, and they do not worry about the development of their baby. They also do not need to experience stress in connection with funding for the care of premature babies, because the incubator and blue light phototherapy equipment is lent out for free without being charged a penny.
\end{abstract}

Keywords: Premature Babies, Incubator, Phototherapy

\section{PENDAHULUAN}

Laporan Perserikatan Bangsa-Bangsa (PBB) 2010 yang berjudul "Born Too Soon, The Global Action Report on Preterm Birth", menempatkan Indonesia pada urutan 5 sebagai negara dengan jumlah bayi prematur terbanyak di dunia (Gozali, 2019). Hal ini di dukung data Biro Pusat Statistik 2016, 
angka kematian bayi (AKB) mencapai 25 kematian setiap 1.000 bayi yang lahir. Hal ini tentu menjadi perhatian berbagai pihak karena $\mathrm{AKB}$ menjadi salah satu indikator tingkat kesehatan sebuah negara.

Penyebab utama kematian neonatal adalah bayi berat lahir rendah (BBLR) termasuk prematuritas, diikuti oleh asfiksia dan infeksi. Bayi prematur adalah bayi yang lahir sebelum akhir usia gestasi 37 minggu, tanpa memperhitungkan berat badan lahir (Wong dkk., 2009). Semakin prematur seorang bayi maka semakin besar risiko kematiannya. Salah satu penyebab kematian pada bayi prematur disebabkan karena hipotermia (7\%), (Riskesdas, 2013). Oleh sebab itu neonatus prematur harus mendapatkan perawatan inkubator di rumah sakit maupun di rumah (Gomella, 2009).

Penurunan $\mathrm{AKB}$ dimulai dengan upaya promotif dan preventif sebelum kehamilan, pada masa kehamilan, persalinan di fasilitas kesehatan dan pelayanan kesehatan neonatal esensial sesuai standar. Bayi yang lahir dengan kondisi BBLR / prematur dilakukan perawatan metode kanguru, dan tatalaksana sesuai dengan kondisi dan komplikasi yang dialami, maupun melalui perawatan dengan menggunakan inkubator, baik di Rumah Sakit, maupun perawatan inkubator portable di rumah.

Inkubator merupakan alat dapat terbuat dari bahan yang sederhana sampai bahan campuran yaitu mulai dari kayu, bahan metal, besi atau bahan plexiglass. Dirancang sedemikian rupa sehingga dapat menciptakan kondisi optimal dalam hal suhu, kelembaban, kelancaran pemberian oksigen, dan cairan untuk kelangsungan hidup seorang bayi. Pengertian lain dari inkubator adalah alat yang dapat mempertahankan suhu lingkungan dalam keadaan optimal sesuai dengan kondisi dalam kandungan ibu yang dapat melindungi dari perubahan suhu lingkungan, sistem metabolisme, respirasi, terhindar dari infeksi dan bayi merasa aman nyaman di dalamnya (Winarti, 2004).
Berbagai usaha telah dilakukan, termasuk di antaranya upaya pemberdayaan masyarakat dalam mempromosikan kesehatan ibu dan anak (KIA), dimana usaha kesejahteraan ibu dan anak bertujuan untuk memberikan pendidikan kesehatan, pencegahan penyakit dan peningkatan kesehatan, penting sekali untuk meningkatkan kesehatan umum dari masyarakat.

Pemberdayaan masyarakat sebagai strategi alternatif dalam pembangunan telah berkembang dalam berbagai literatur dan pemikiran walaupun dalam kenyataannya belum secara maksimal dalam implementasinya. Pembangunan dan pemberdayaan masyarakat merupakan hal banyak dibicarakan masyarakat karena terkait dengan kemajuan dan perubahan bangsa ini ke depan apalagi apabila dikaitkan dengan skill masyarakat yang masih kurang akan sangat menghambat pertumbuhan ekonomi itu sendiri. (Noor, 2011).

Adapun program kegiatan yang dilakukan dalam kegiatan KIA adalah melayani kesehatan ibu, bayi dan anak sampai umur 5 tahun. Di Indonesia diperkirakan jumlah ibu menyusui dan ibu yang hamil kurang lebih $7 \%$ dan anak umur 0-5 tahun kurang lebih 18\%. Jadi jumlah yang harus dilayani Dinas KIA adalah 25\% dari seluruh penduduk.

Melihat pada fenomena yang terjadi di atas, terlebih di daerah Sumatera Utara, berdasarkan data Badan Statistik Pemerintahan (BSP) Provinsi Sumut, melaporkan bahwa, dari 291.363 angka kelahiran, terdapat 1.250 bayi yang lahir dengan prematur. (Data BSP Provinsi SU, 2017), khususnya daerah Pemerintahan Kota Pematangsiantar, dimana masih banyak di temukan bayi-bayi BBLR yang tidak mendapatkan perawatan yang prima oleh karena harus pulang dari Rumah Sakit, dan adanya keterbatasan pembiayaan, sekaligus dalam momen Hari Prematuritas Sedunia yang diperingati setiap tanggal 17 November, Institusi Akademi Keperawatan Surya Nusantara, Pematangsiantar, dalam 
hal ini salah seorang Staf pengajar di Akper yang terdaftar sebagai relawan inkubator gratis Indonesia, yang bernama Pipin Sumantri, untuk wilayah Sumatera Utara khususnya Kota Siantar dan sekitarnya, telah bekerja sama dengan Yayasan Bayi Prematur Indonesia, dan tim inkubator gratis Universitas Indonesia (Fakultas Teknik).

Pada saat ini Tim relawan inkubator gratis Akper Surya Nusantara memiliki 4 unit inkubator portable beserta dengan penghangat (fototerapi) untuk perawatan bayi prematur, penyediaan inkubator gratis tersebut terlaksana oleh kebaikan sponsor yaitu bapak Antoni Sihombing 2 unit inkubator (Jakarta), serta Bapak Bambang Waringin (Medan), yang juga telah menghibahkan 2 inkubator miliknya untuk di pergunakan menolong para bayi yang baru lahir yang ada di wilayah kerja relawan inkubator gratis Akper Surya Nusantara. Tim relawan inkubator gratis Akper Surya Nusantara telah meminjamkan ke beberapa orang tua yang memiliki bayi BBLR untuk mendapatkan peminjaman Inkubator Gratis, serta konsultasi perawatan bayi prematur. Dengan kegiatan PKM ini di harapkan angka kejadian kematian bayi prematur dapat berkurang, serta meminimalkan tingkat stres orang tua (ibu) dalam perawatan bayi BBLR.

\section{METODE}

Adapun metode pelaksanaan PKM ini melalui strategi pendekatan kepada masyarakat dalam bentuk promosi peminjaman inkubator gratis kepada para keluarga yang memiliki bayi-bayi yang prematur. Pendekatan dilakukan secara langsung (direct approach) dengan menggunakan komunikasi yang efektif kepada para tenaga kesehatan yang terdapat di sekitar wilayah kerja, serta para tokohtokoh masyarakat, dalam hal ini kepala desa, para tenaga kesehatan (bidan), maupun para lurah yang terdapat di sekitar wilayah kerja peminjaman Inkubator Gratis.
Kegiatan PKM ini diawali dengan memberikan sosialisasi kepada para masyarakat desa, baik secara individu, maupun kelompok. Kegiatan ini bertujuan memberikan pengetahuan bahwa bayi-bayi yang mengalami prematur, perlu menggunakan inkubator, untuk menyesuaikan suhu bayi tersebut, sehingga bayi tersebut dalam keadaan sehat dan bertumbuh secara normal.

\section{HASIL DAN PEMBAHASAN}

Adapun proses peminjaman inkubator gratis ini, diawali dengan pengisian daftar kontrak peminjaman Inkubator, dimana relawan akan menjelaskan Standard Operasional Prosedur (SOP) penggunaan alat inkubator tersebut, pihak keluarga akan mendapatkan penjelasan mengenai penggunaan inkubator tersebut, selain itu, pihak relawan akan menyampaikan bahwa inkubator tersebut hanya bersifat peminjaman, dan bukan menjadi hal milik, apabila relawan melihat bahwa perkembangan bayi tersebut sudah mulai membaik, maka pihak keluarga bersedia mengembalikan inkubator tersebut, untuk di pinjamkan kepada bayi yang lain yang kondisinya lebih memerlukan.

Dengan kegiatan pengabdian pada masyarakat dalam melalui program peminjaman inkubator gratis yang telah dilakukan, banyak para orang tua yang memiliki bayi BBLR merasa tertolong dan sangat berterima kasih, proses peminjaman inkubator yang telah di pinjamkan kepada para orang tua berkisar antara 1 sampai 2 bulan, namun ada juga pihak keluarga yang meminjam lebih dari 3 bulan, hal ini dikarenakan kondisi bayi yang sulit berkembang, berikut peminjam inkubator/fototerapi gratis yang telah dilayani oleh relawan inkubator gratis Akademi Keperawatan Surya Nusantara dapat dilihat pada tabel 1 dibawah ini. 
Tabel 1.

Daftar Data Peminjam Incubator Gratis dan Alat Fisioterapi

\begin{tabular}{|c|l|l|l|l|l|l|l|}
\hline No & Nama Ortu & $\begin{array}{c}\text { Nama } \\
\text { Bayi }\end{array}$ & Kasus & Umur & $\begin{array}{c}\text { BB } \\
\text { Awal }\end{array}$ & $\begin{array}{c}\text { BB } \\
\text { Akhir }\end{array}$ & \multicolumn{1}{|c|}{ Alamat } \\
\hline 1. & $\begin{array}{l}\text { Erwin } \\
\text { Hariady }\end{array}$ & Naila & BBLR & 54 hari & $1.5 \mathrm{~kg}$ & $2.5 \mathrm{~kg}$ & $\begin{array}{l}\text { Perumahan DL Sitorus, Jln } \\
\text { Medan Km 2, } \\
\text { Pematangsiantar }\end{array}$ \\
\hline 2. & $\begin{array}{l}\text { Rolan } \\
\text { Ginting }\end{array}$ & Betty & BBLR & 17 hari & $1.1 \mathrm{~kg}$ & $2.2 \mathrm{~kg}$ & $\begin{array}{l}\text { Huta 3 Simp Tiga Nagori } \\
\text { Silau Malaha, Tanah Jawa, } \\
\text { Simalungun }\end{array}$ \\
\hline 3. & $\begin{array}{l}\text { Leo Rico } \\
\text { Simbolon }\end{array}$ & $\begin{array}{l}\text { Olivia } \\
\text { Mujizat } \\
\text { Simbolo } \\
\text { n }\end{array}$ & BBLR & 12 hari & $1.1 \mathrm{~kg}$ & $2.5 \mathrm{~kg}$ & Dolok Masihol, Simalungun \\
\hline 4. & $\begin{array}{l}\text { Arseniur } \\
\text { Aritonang } \\
\text { Aritonan } \\
\text { g }\end{array}$ & BBLR & 5 Hari & $1.5 \mathrm{~kg}$ & $2.7 \mathrm{~kg}$ & $\begin{array}{l}\text { Bukit Maratur, Tanjung } \\
\text { Pinggir, Pematangsiantar }\end{array}$ \\
\hline 5. & $\begin{array}{l}\text { Eko Pramata } \\
\text { Isabella }\end{array}$ & BBLR & 45 hari & $1.2 \mathrm{~kg}$ & $2.6 \mathrm{~kg}$ & $\begin{array}{l}\text { Jln Medan, Simp Mesjid, } \\
\text { Pematangsiantar }\end{array}$ \\
\hline 6. & $\begin{array}{l}\text { Janser P } \\
\text { Silitonga }\end{array}$ & $\begin{array}{l}\text { Yesaya } \\
\text { Anugra } \\
\text { Silitonga }\end{array}$ & BBLR & 12 hari & $1.5 \mathrm{~kg}$ & $2.9 \mathrm{~kg}$ & $\begin{array}{l}\text { Jln Laucumba gg Masiurupan, } \\
\text { Pematangsiantar }\end{array}$ \\
\hline 7. & $\begin{array}{l}\text { Melika } \\
\text { Nainggolan }\end{array}$ & $\begin{array}{l}\text { Otniel } \\
\text { Sinaga }\end{array}$ & BBLR & 12 hari & $1.6 \mathrm{~kg}$ \\
\hline 8. & $\begin{array}{l}\text { Rismawani } \\
\text { Hutagalung } \\
\text { Naibaho }\end{array}$ & $\begin{array}{l}\text { Hyperbil } \\
\text { irubin }\end{array}$ & 7 hari & $3.0 \mathrm{~kg}$ & $3.3 \mathrm{~kg}$ & $\begin{array}{l}\text { Jiga Dolok } \\
\text { Pematangsiantar }\end{array}$ \\
\hline
\end{tabular}

Gambar 1.

Grafik Perkembangan Berat Badan Bayi Prematur

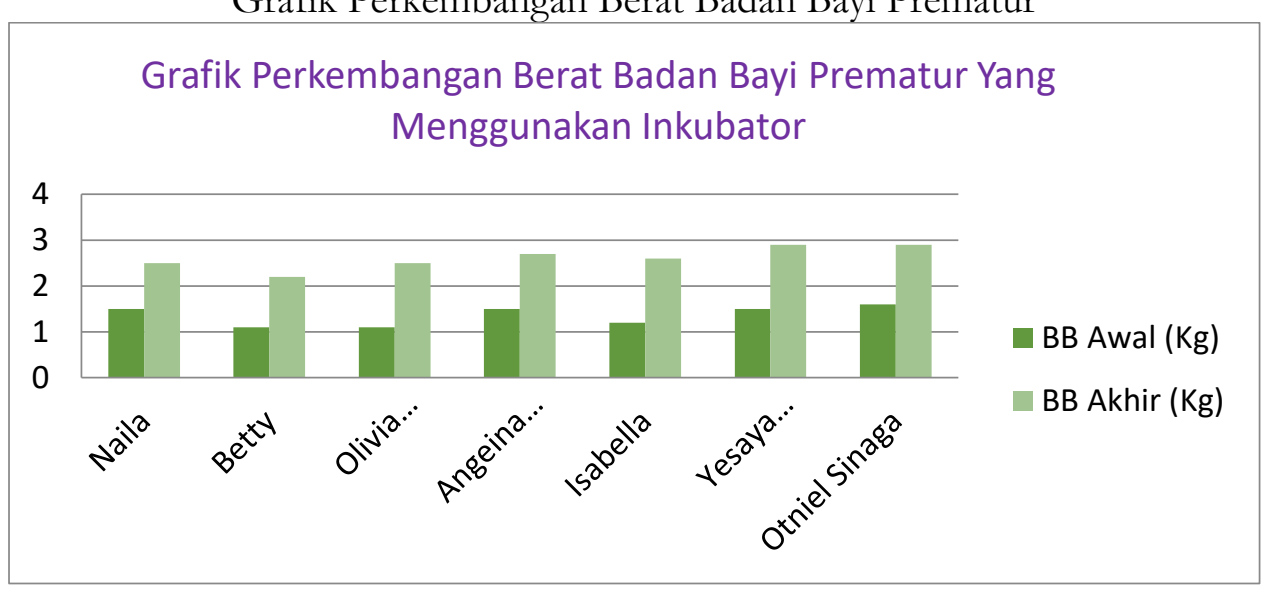

Melalui grafik di atas, dapat dilihat bahwa melalui perawatan bayi prematur di inkubator, para bayi prematur tersebut dapat bertumbuh dengan baik, serta tidak mengalami gangguan bypothermi (dingin), dan kesehatan bayi prematur tersebut semakin lama semakin membaik, dan bayi tersebut dapat bertumbuh dengan normal seperti bayi-bayi yang lahir normal lainnya. 
Gambar 2

Keterangan gambar kegiatan PKM Inkubator Gratis

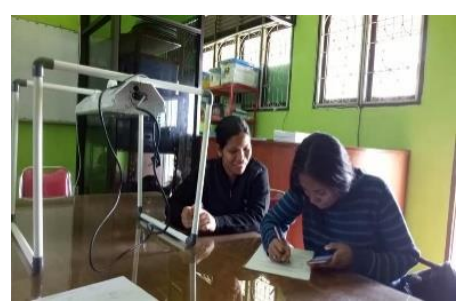

1

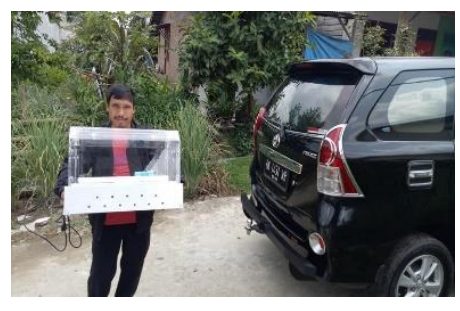

4

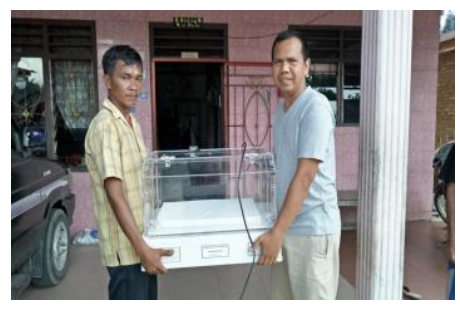

7

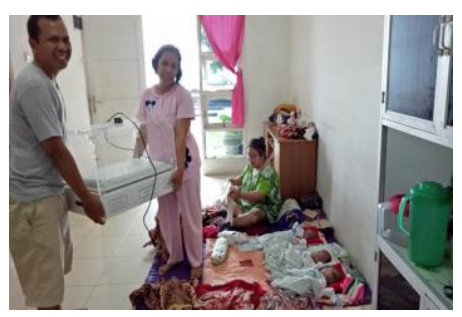

10

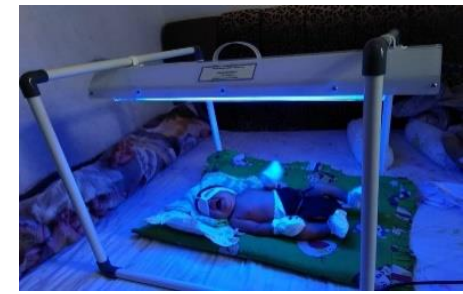

2

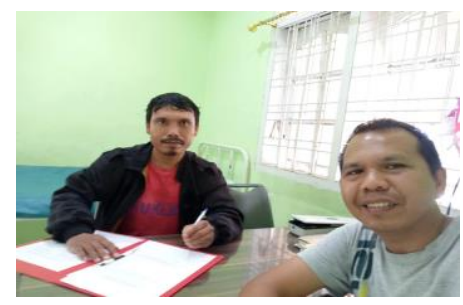

5

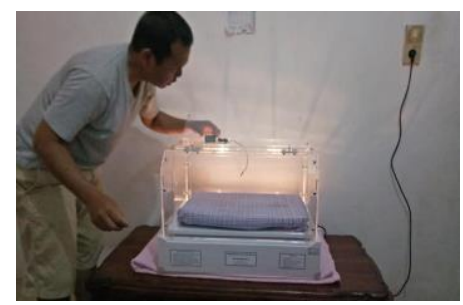

8

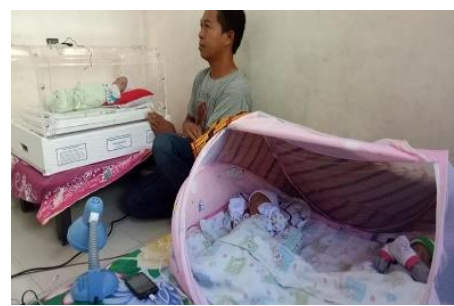

11

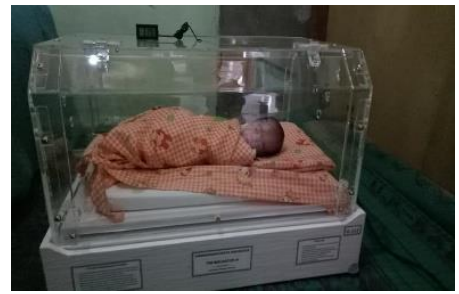

3

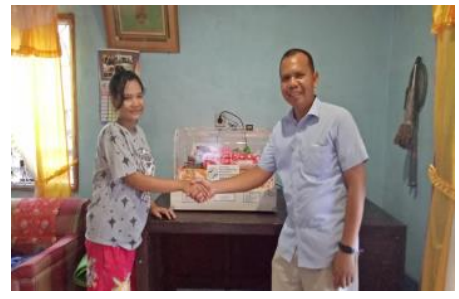

6

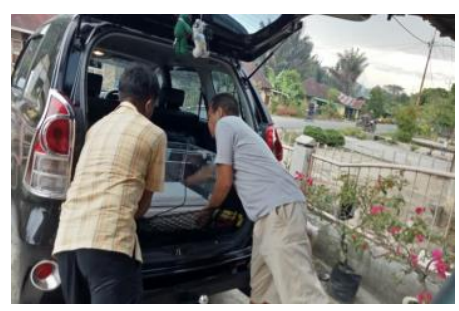

9
Keterangan gambar:

1. Keluarga bayi dengan byperbilirubin melakukan pengisisan formulir untuk peminjaman alat fototerapi sinar blue light untuk menurunkan byperbilirubin bayi mereka.
2. Alat fototerapi sinar blue light yang telah di gunakan bayi untuk menurunkan kadar byperbilirubin.

3. Bayi dengan BBLR yang sedang menggunakan inkubator portable yang di pinjamkan oleh Relawan Inkubator

Peminjaman Inkubator Gratis Bagi Bayi Prematur

Pipin Sumantrie, Martalina Limbong

DOI: https://doi.org/10.26714/jism.3.1.2020.48-54 
Gratis yang bekerja sama dengan Yayasan Bayi Prematur Indonesia dan Tim Inkubator Gratis UI.

4. Orang tua bayi prematur yang beruntung mendapatkan alat inkubator portable yang akan di pergunakan untuk bayi mereka yang mengalami prematur pada saat lahir.

5. Orang tua bayi prematur yang melakukan pengisian formulir peminjaman inkubator gratis yang akan diantar ke rumah mereka.

6. Penyerahan inkubator gratis kepada keluarga yang membutuhkan perawatan bayi dengan menggunakan inkubator portable.

7. Penyerahan inkubator gratis kepada keluarga yang membutuhkan perawatan bayi dengan menggunakan inkubator portable.

8. Proses pengecekan suhu inkubator sebelum di gunakan oleh bayi prematur.

9. Proses pengantaran serta penyerahan inkubator portable kepada keluarga yang membutuhkan perawatan bayi yang membutuhkan inkubator portable.

10. Proses pengantaran serta penyerahan inkubator portable kepada keluarga yang membutuhkan perawatan bayi yang membutuhkan inkubator portable.

11. Orang tua bayi prematur yang sedang menunggu dan merawat bayi mereka yang menggunakan inkubator portable .

\section{KESIMPULAN}

Dengan tersedianya peminjaman inkubator portable gratis yang dilakukan oleh relawan inkubator gratis Akademi Keperawatan Surya Nusantara, bekerja sama dengan Yayasan Bayi Prematur Indonesia, para masyarakat Pematangsiantar dan sekitarnya merasa tertolong, dan sangat berterima kasih, bukan hanya bayi prematur yang merasa nyaman dengan berada di dalam inkubator tersebut, para orang tua juga merasa bahagia, dan tidak kuatir akan perkembangan bayi mereka, dan mereka tidak perlu mengalami stres sehubungan dengan pembiayaan dalam perawatan bayi prematur, karna alat inkubator dan alat fototerapi blue light di pinjamkan secara gratis tanpa di pungut biaya sepeser pun, bahkan pihak relawan akan mengantar alat tersebut ke rumah keluarga, serta melakukan monitoring perkembangan bayi prematur melalui kunjungan langsung ke rumah dua minggu sekali.

Relawan inkubator gratis Akper Surya Nusantara, adalah satu-satunya relawan inkubator gratis yang terdapat di wilayah Sumatera Utara, kegiatan ini adalah bersifat sosial dan tidak mencari keuntungan, pada saat ini relawan inkubator gratis Akper Surya Nusantara, mengalami kesulitan dalam memenuhi permintaan orang tua yang berada di luar Pematangsiantar. Kita bisa berkontribusi menjadi relawan inkubator gratis melalui bekerja sama dengan Yayasan Bayi Prematur Indonesia dan Tim Inkubator UI dengan cara mendonasikan alat inkubator portable tersebut kepada relawan yang di tunjuk, atau langsung menjadi relawan inkubator gratis untuk membantu para bayi-bayi prematur yang ada di sekitar wilayah kerja relawan. Hidup ini adalah kesempatan, mari melakukan pengabdian kepada masyarakat melalui bergabung dengan Tim relawan inkubator gratis Indonesia.

\section{DAFTAR PUSTAKA}

Badan Pusat Statistik (BPS) Pemerintah Pusat Sumatera Utara. https://sumut.bps.go.id/statictable/ 2018/11/28/1289/jumlah-bavi-lahirbayi-berat-badan-lahir-rendah-bblrbblr-dirujuk-dan-bergizi-burukmenurut-kabupaten-kota-di-provinsisumatera-utara-2017.html

Gomella, T. L. (2009). Neonatologi Management, Procedur, On-Call Problem Diseassea, and Drugs.Sixth Edition. North America: Mc GrawHill Company

Gozali. Salahuddin. (2019). https://health.grid.id/read/3515976 76/indonesia-urutan-5-jumlah-bayi- 
prematur-terbanyak-di-dunia-risiko-

rop?page $=$ all

Noor (2011), Pemberdayaan masyarakat., Jurnal Ilmiah CIVIS, Volume I, No 2, Juli 2011, hal 87-99.

Riset Kesehatan Dasar. (2013). Jakarta:Departemen Kesehatan RI.

Winarti, W. (2004). Mengenal Inkubator Penggunaan dan Pemeliharaan. Bandung.

Wong, D L, Easton. M. H, Wilson, H, Winkelstein, M. L, and Schwartz, P. (2009). Buku Ajar Keperawatan Pediatrik: Alih Bahasa Agus Sutarna, Neti Juniarti, H.Y Kuncara. Jakarta: EGC 